\title{
DOENÇAS DO CORPO VÍTREO, RETINA E UVEÍTE
}

\author{
VITREOUS, RETINA AND UVEITES
}

Nivaldo Vieira de Souza

Docente do Departamento de Oftalmologia e Otorrinolaringologia da Faculdade de Medicina de Ribeirão Preto da Universidade de São Paulo.

CORRESPONDÊNCIA: Departamento de Oftalmologia e Otorrinolaringologia da Faculdade de Medicina de Ribeirão Preto - Hospital das Clínicas - Campus Universitário - CEP: 14048-900 - Ribeirão Preto - SP.

SOUZA, NV de. Doenças do corpo vítreo, retina e uveíte. Medicina, Ribeirão Preto, 30: 69-73, jan./mar. 1997.

RESUMO: Este capítulo trata de problemas do corpo vítreo, problemas da retina e de uveítes, iniciando com noções de Embriologia e com a descrição do fundo de olho normal.

UNITERMOS: Corpo Vítreo. Retina. Uveíte.

\section{EMBRIOLOGIA}

Durante a quarta semana de vida embrionária, ocorre a invaginação da vesícula óptica, formando o cálice óptico com dupla camada de células neuroectodérmicas. Sua face interna limita o espaço cheio de tecido mesenquinal, denominado de corpo vítreo primário, constituído por tecido conjuntivo, em cuja porção mais central se encontra o sistema vascular hialóideo. Posteriormente, este tecido primitivo se transformará, com a regressão total dos vasos hialóideos, no corpo vítreo secundário, com as características do adulto, já à época do nascimento.

O mesênquima junto à camada externa do cálice óptico, pelo segundo mês de vida embrionária, começa a tomar a forma de um plexo vascular, que será a futura úvea, seus vasos nutridores, artérias ciliares posteriores e anteriores e seu sistema de drenagem, representado, no adulto, pelas veias vorticosas. No final do quinto mês, as diferentes camadas da úvea já estão definidas e esta começa a adquirir sua pigmentação característica, com a presença dos melanossomas primitivos, no sétimo mês de vida fetal.
A camada neuroectodérmica interna vai dar origem aos diferentes tipos de células da retina sensorial (fotorreceptores, células bipolares, células ganglionares, células amácrimas, interplexiformes e horizontais, células de Muller e gliais), enquanto a externa adquire grande quantidade de pigmento e se diferencia numa camada celular única (Epitélio Pigmentar da Retina). O cálice óptico apresenta ínfero-nasalmente uma fissura que inicia seu fechamento da porção anterior para a posterior no final da quarta semana. Essa fissura é atravessada pela artéria hialóidea, a qual posteriormente (no final do terceiro mês) atrofia e desaparece.

Pelo quarto mês de vida fetal, aparecem os primeiros esboços do que será a futura vascularização da retina, iniciando com um botão endotelial, na cabeça do nervo óptico, que se diferenciará na artéria central da retina. O completo desenvolvimento do sistema vascular retiniano só se fará pelo quinto mês após o nascimento. Também, algumas outras estruturas retinianas vão estar completamente formadas após o nascimento, por exemplo, a mácula que vai estar diferenciada pelo quarto mês pós-natal, o que explica o aparecimento da fixação por esta época. 


\section{FUNDO DE OLHO NORMAL}

A coloração avermelhada do F.O., vista na oftalmoscopia, deve-se à malha dos vasos sangüíneos da coróide, uma vez que a retina propriamente dita é transparente, sendo visíveis somente seus vasos sangüíneos, em condições normais. Esta tonalidade avermelhada do F.O. normal pode ser alterada pela maior ou menor densidade de pigmento encontrado no epitélio pigmentado da retina.

A transparência da retina é essencial à boa acuidade visual, uma vez que os fotorreceptores estão na camada mais profunda da retina sensorial, em contato com o epitélio pigmentar (importante no metabolismo dos fotorreceptores), portanto, tendo a luz que atravessar todas as camadas da retina. A retina recobre $2 / 3$ da porção interna posterior do globo ocular, estando fortemente aderida na borda do disco óptico e na sua terminação anterior, chamada de ora serrata. A retina sensorial está frouxamente aderida ao epitélio pigmentar da retina, havendo entre eles um espaço virtual de origem embrionária, que pode se tornar real em algumas situações patológicas, que determinam a perda da força de adesão. A face da retina encontra-se em contato com o humor vítreo, com quem, inclusive, apresenta continuidade através das fibras colágenas, na região da ora serrata, constituindo o que chamamos de vítreo-base. Outros pontos de aderência, mais frágeis, estão ao redor do disco óptico, na área macular e ao longo dos vasos sangüíneos.

Os ramos vasculares, artérias e veias, temporal superior, temporal inferior, nasal superior, nasal inferior, originários da artéria e veia centrais da retina, ao nível da papila, percorrem a superfície da retina e vão nutrir as camadas mais internas da mesma, enquanto o $1 / 3$ externo recebe sua nutrição diretamente dos coriocapilares, pela difusão seletiva através do epitélio pigmentar da retina.

O pólo posterior (anatomicamente denominado área centralis) é uma região de mais ou menos $6 \mathrm{~mm}$ de diâmetro, limitada pelas arcadas vasculares temporal superior e inferior e centrada numa região de aspecto mais escuro - fóvea, com $0,5 \mathrm{~mm}$ de diâmetro, situada há cerca de $21 / 2$ discos de diâmetro da papila e ligeiramente inferior à mesma, a qual, histologicamente, se apresenta como uma depressão (fovéola para os anatomistas), uma vez que a retina, nesta área, é formada somente por fotorreceptores, particularmente cones, faltando todas as outras camadas, as quais são "empurradas" para a margem da fóvea, for- mando área ovalada chamada mácula lútea, devido sua coloração levemente amarelada pelo acúmulo de pigmento xantofílico (esta região é denominada pelos anatomistas de fóvea).

A região equatorial da retina corresponde ao maior diâmetro vertical e horizontal do globo ocular, isto é, cerca de $24 \mathrm{~mm}$. A projeção escleral do equador do olho fica cerca de $12 \mathrm{~mm}$ do limbo e o ponto de referência, na retina, são os botões das veias vorticosas, que se encontram aproximadamente dois discos de diâmetro posterior ao equador do olho.

Finalmente, a retina periférica é a porção mais anterior que termina na ora serrata, de aspecto denteado, com prolongamentos anteriores em direção ao corpo ciliar, chamados "dentes", e concavidades voltadas para as anteriormente chamadas "baias". A projeção externa da ora serrata corresponde aos pontos de inserção dos músculos retos.

\section{DOENÇAS DO CORPO VÍTREO}

O corpo vítreo, no adulto, é uma estrutura relativamente inerte, constituído por $99 \%$ de água, sendo o material sólido, representado por fibras colágenas, ácido hialurônico e raras células - hialócitos. Este tecido não oferece praticamente nenhuma reação e seu comprometimento, com perda da transparência, ocorre por alterações dos tecidos adjacentes (retina e coróide) com hemorragias e exsudatos vítreos (ver cap. Opacidade dos meios oculares).

A degeneração vítrea é geralmente um processo senil, conseqüente à alteração no ácido hialurônico e aparecimento de vesículas líquidas no corpo vítreo. Sem significante alteração visual, estes pacientes podem se queixar da sensação de figuras escuras (pontos, linhas, teias de aranha, etc) no campo visual - moscas volantes. Com o avanço do processo, estas vesículas coalescem e podem chegar à borda do vítreo, separando-o da retina - deslocamento posterior do vítreo - situação que, muitas vezes, provoca pequenas trações sobre a retina sensorial e a sensação de luz - fotopsia.

Alterações no corpo vítreo, propriamente, com significante perda visual, são geralmente congênitas:

Persistência do Vítreo Primário Hiperplástico: quase sempre unilateral com grande desorganização do globo ocular e, mau prognóstico visual. Pode existir na forma anterior, com massa branca, logo atrás do cristalino pela hiperplasia do vítreo primário ou posterior, quando se inicia na região da papila. 
Persistência da Artéria Hialóide: acomete, geralmente, prematuros devido à não-regressão do sistema hialóide, que pode ser parcial ou total, com fibrose esbranquiçada desde a papila até o cristalino, mas, geralmente, não interferindo na visão.

\section{DOENÇAS DA RETINA}

Encontramos alterações patológicas na retina, em todas as faixas etárias, desde o nascimento até a velhice, sendo as mais freqüentes:

\section{Retinopatia na Prematuridade}

Esta é uma patologia cujos fatores de risco ainda não estão perfeitamente definidos, mas, hoje, se admite que a prematuridade, o baixo peso ao nascer e o ambiente rico em $\mathrm{O}_{2}$ são importantes no aparecimento da doença. Se nos lembrarmos da embriologia da retina, vemos que seu sistema vascular não está perfeitamente desenvolvido ao nascimento, em especial na retina periférica, assim, quando colocado em ambiente com alta concentração de oxigênio, ocorrem alterações que determinam o menor desenvolvimento dos capilares. Posteriormente, quando a criança, já desenvolvida, é colocada no ambiente normal, é como se a retina estivesse sob condições de hipóxia e, a partir daí, inicia-se a formação reativa de membranas neovasculares, que crescem para o humor vítreo, formando o quadro típico de uma membrana retrocristaliana (daí o nome de fibroplasia retrolental) que pode tracionar a retina e provocar seu descolamento. O tratamento depende do estágio da doença e deve ser efetuado por especialista. As crianças prematuras devem ser acompanhadas por oftalmologistas até o terceiro mês de vida pós-natal, período em que pode haver ainda o progresso da retinopatia.

\section{Doença de Stargardt:}

Distrofia juvenil bilateral que determina graves perdas da visão em período relativamente curto, com fundo de olho ainda normal, mas que, com o passar do tempo, vai apresentando alterações pigmentares na mácula até tomar aspecto rugoso característico. Alguns casos podem estar associados a lesões no segmento posterior do olho, semelhantes ao fundus flacimaculatus. É transmitida por herança autossômica recessiva.

\section{Retinose Pigmentar}

É doença hereditária, onde o fator consangüinidade é muito freqüente, e cuja principal manifestação é a cegueira noturna, isto é, grande dificuldade de se adaptar ao escuro. No fundo de olho, apresenta pigmentação negra sob forma de espículas (osteoclastos), regional ou generalizada, e evolue para a atenuação dos vasos sangüíneos e palidez da papila. Esta doença manifesta-se geralmente na puberdade. Além da hemeralopia há perda progressiva do campo visual e posteriormente da visão central.

\section{Degeneração Miópica}

As altas miopias se caracterizam por lesões evolutivas em todas as estruturas oculares, sendo as alterações mais precoces e importantes, do ponto de vista funcional, aquelas presentes no pólo posterior. Observamos uma ectasia escleral que determina um estafiloma posterior. Há atrofia coriorretiniana, peripapilar, alterações pigmentares na mácula e roturas na membrana de Bruch, que leva à formação de membrana neovascular sub-retiniana, vinda dos coriocapilares. Esta pode sangrar, formando, na mácula, uma mancha escura, responsável pela perda da visão central, chamada mancha de Foster-Fuchs. Há, no pólo posterior, estreitamento vascular e palidez pela atrofia do epitélio pigmentar da retina e coriocapilares. $\mathrm{Na}$ retina periférica, aparecem degenerações que predispõem ao deslocamento de retina.

\section{Corio-retinopatia Serosa Central:}

Este processo patológico de etiologia ainda não determinada afeta principalmente pacientes masculinos (90\%) com idade média de 40 anos (20 a 60 anos). Há queda de visão central, que, em alguns casos, melhora com lentes positivas, metamorfopsia, micropsia e cromatopsia. O processo é devido à rotura da barreira coroidorretiniana, por disfunção do epitélio pigmentar, e conseqüente acúmulo de líquido seroso sob a retina sensorial na área foveal, em alguns casos, podendo estar associado a descolamentos do epitélio pigmentar da retina. O quadro tem evolução geralmente benigna, com cicatrização espontânea da lesão em um ou dois meses, deixando alteração pigmentar e recuperação total da visão. Entretanto, há recidiva em $1 / 3$ dos casos, para o que se propõe a fotocoagulação.

\section{Oclusão Venosa:}

A trombose venosa é um processo geralmente unilateral, freqüente em indivíduos idosos, arterioscleróticos e que pode deixar grandes prejuízos visuais. Os principais locais de trombose são a nível da lâmina crivosa na papila, provocada pela compressão da veia pela artéria endurecida, levando à oclusão da 
veia central da retina e/ou à borda da papila, onde a artéria cruza a veia, podendo comprimi-la, uma vez que, nestes locais, a adventícia é comum aos dois vasos, formando um anel.

O quadro fundoscópico é de edema retiniano e hemorragia, inicialmente superficial e que logo compromete as camadas mais profundas. Na região afetada, as placas hemorrágicas se espalham do disco óptico à periferia e podemos, às vezes, pelo sofrimento da camada de fibras nervosas, encontrar exsudatos algodonosos. As veias, inicialmente, apresentam-se dilatadas e, posteriormente, dependendo da gravidade do quadro, podemos ter estreitamento arteriolar. A causa mais freqüente é, sem dúvida, a hipertensão arterial, acompanhada de arteriosclerose. Também alterações sangüíneas (p. ex., anemia), condições locais, como a periflebite e glaucoma, estão entre suas causas, principalmente em pacientes mais jovens. Na evolução, pode haver recuperação da visão, principalmente nos quadros mais brandos, sem grande comprometimento da área macular. Em algumas semanas, as hemorragias vão se reabsorvendo, deixando pigmentos hemáticos, dispersos na retina. Como sequiela, geralmente, ficam colaterais tortuosas, que se abriram na papila, para constituir anastomoses compensadoras e depósito pigmentar na mácula. Estes pacientes devem ser mantidos em observação por meses, pois podem desenvolver complicações graves, como glaucoma secundário e neovascularização retiniana. Não há tratamento específico, o efeito de anticoagulante é muito discutido, as complicações secundárias, como glaucoma, devem ser abordadas especificamente, e as neovascularizações destruídas com fotocoagulação.

\section{Degeneração Macular relacionada com idade ou Degeneração Macular Senil (DMS)}

Esta patologia é uma das principais causas de cegueira, nos pacientes idosos, e devido a alterações na túnica Ruyschiana (epitélio pigmentar da retina, membrana de Bruch e coriocapilares). As alterações histológicas são visíveis à Oftalmoscopia, numa fase precoce, como nódulos irregulares, amarelo-esbranquiçados, no pólo posterior - drusas - pelo acúmulo de catabólitos das células do epitélio pigmentar, na membrana de Bruch. Sob microscopia, entretanto, as alterações são mais extensas, podendo comprometer as três camadas.

A Degeneração Macular Senil (DMS) apresenta uma forma seca em que há alteração anatômica e funcional na túnica Ruyschiana, revelada oftalmoscopicamente por uma placa atrófica com pigmentação e aspecto irregular na mácula. $\mathrm{Na}$ forma exsudativa da D.M.S., há formação de uma membrana neovascular, originária da coróide, que invade a camada mais interna da membrana de Bruch, trazendo, como conseqüência, uma lesão disciforme hemorrágica, a qual vai terminar na formação de cicatriz fibrosa.

\section{Deslocamento de Retina:}

É um processo de etiologia multifatorial, que se caracteriza pela reabertura do espaço embrionário existente no cálice óptico entre as duas camadas neuroectodérmicas; isto, em realidade, significa uma separação da retina sensorial do epitélio pigmentar e não um verdadeiro deslocamento de retina, que seria a separação desta da Membrana de Bruch.

Diversos fatores, agindo sobre retina, humor vítreo e coróide, são os determinantes do aparecimento do líquido entre retina sensorial e epitélio pigmentado - líquido sub-retiniano. Este poderá vir do humor aquoso através de roturas retinianas (buracos, rasgões ou diálises), ter origem na própria retina ou na coróide. Trações vítreas podem produzir ou roturas na retina ou puxar a retina, despregando-a do epitélio pigmentado. Assim, podemos ter D.R. regmatogênico, quando a rotura retiniana está presente, podendo ser espontânea, em pontos onde a retina está atrofiada, ou provocada por tração, nos deslocamentos posteriores de vítreo ou nos traumatismos - D.R. tracional - em que o principal componente está nas trações do vítreo sobre a retina (por exemplo, nas retinopatias diabéticas e da prematuridade) e D.R. exsudativo (seroso ou hemorrágico), que ocorre, geralmente, em neoplasias, inflamações, hipertensão maligna, toxemia da gravidez, etc., situações que comprometem a função do epitélio pigmentar e coróide. Esta classificação, como todas, é simplista, pois o que encontramos, na maioria dos casos, é a associação de vários fatores.

Para exame do paciente, com descolamento de retina, são indispensáveis a oftalmoscopia indireta e o exame do humor vítreo com biomicroscopia e lentes, com o que mapeamos a retina e identificamos os fatores atuantes, tais como roturas (rasgões, buracos e diálises), trações e fibroses vítreas, neoplasias, etc.

O tratamento é sempre cirúrgico, sob anestesia geral ou local, e consiste em se repor a retina de encontro ao epitélio pigmentar, através de implantes de silicone epi ou intra-esclerais, localizados ou com uma cintagem em $360^{\circ}$ ou através de injeção intravítrea de gases expansivos $\left(\mathrm{SF}_{6}, \mathrm{C}_{3} \mathrm{~F}_{8}\right.$, etc.) ou através de introflexão da própria esclera, associados ou não à vitrec- 
tomia. Com isso, podemos promover o reassentamento da retina e, então, provocar adesão dos dois folhetos - RETINOPEXIA - usando diatermocoagulação, criocoagulação ou fotocoagulação (xênonio ou laser).

A escolha da técnica cirúrgica vai depender da etiologia do deslocamento, do volume líquido subretiniano, extensão, número e localização das roturas, condições do humor vítreo, etc, além da importância de fatores sistêmicos, como idade, condições físicas, patologias associadas, etc.

Atualmente, o sucesso dessas operações é muito alto, principalmente nos casos de descolamentos recentes com alterações visuais mínimas, apesar das alterações histológicas presentes a nível de fotorreceptores e do epitélio pigmentado e mudanças na refração, nos implantes maiores.

\section{UVEÍTES}

Os processos inflamatórios de origem exôgena ou endógena são, de longe, a mais freqüente doença da úvea. Conforme a localização nós podemos ter:

Iridociclite: processo inflamatório anterior, comprometendo íris e corpo ciliar, geralmente, com dor e leve turvação da visão. Ao exame, encontramos exsudação protêica e celular na câmara anterior.

Uveíte Intermediária: seu diagnóstico nem sempre é fácil, pois, geralmente, não há queixa clínica, a não ser quando ocorre edema de mácula (perda da visão central). Há formação de nódulos esbranquiçados, pouco exsudativos na ora serrata e pars plana, região de difícil exame.

Coriorretinite: pelo contato íntimo, as inflamações da coróide, quase sempre, afetam a retina com quadro clínico muito variável. Geralmente, apresentam-se como lesão focal esbranquiçada com exsudação de intensidade variável ao redor, podendo, pela turvação do humor vítreo, determinar acentuada baixa visual, geralmente sem dor e hiperemia conjuntival.

No nosso meio, o agente etiológico mais freqüente das coriorretinites é o toxoplasma gondii. $\mathrm{O}$ tratamento das uveítes, quando feito o diagnóstico etiológico, é específico, entretanto, em quase todas elas, está indicado o uso de corticosteróide tópico e/ou sistêmico, para impedir a exsudação que, quando intensa, pode deixar, como seqüela, uma deficiência visual definitiva.

SOUZA, NV de. Vitreous, retina and uveites. Medicina, Ribeirão Preto, 30: 69-73, jan./march 1997.

ABSTRACT: In this section are explained problems of vitreous, retina diseases and uveites, starting with basic aspects of embriology and normal fundus.

UNITERMS: Vitreous Body. Retina. Uveitis. 